\title{
Daily Dynamics of Personal Identity and Self-concept Clarity
}

\author{
SETH J. SCHWARTZ ${ }^{1 *}$, THEO A. KLIMSTRA ${ }^{3 \dagger}$, KOEN LUYCKX ${ }^{3}$, WILLIAM W. HALE III $^{2}$, TOM FRIJNS ${ }^{2}$, \\ ANNERIEKE OOSTERWEGEL ${ }^{2}$, POL A. C. VAN LIER ${ }^{4}$, HANS M. KOOT ${ }^{4}$ and WIM H. J. MEEUS ${ }^{2}$ \\ ${ }^{1}$ Department of Epidemiology and Public Health, University of Miami, USA \\ ${ }^{2}$ Research Centre on Adolescent Development, Utrecht University, The Netherlands \\ ${ }^{3}$ School Psychology and Adolescent Development (SCAD), Catholic University of Leuven, Belgium \\ ${ }^{4}$ Faculty of Psychology, VU University Amsterdam, The Netherlands
}

\begin{abstract}
We examined the daily dynamics among self-concept clarity and identity processes, and their effects on distress, among a sample of 580 Dutch adolescents. Participants completed measures of identity, self-concept clarity, anxiety and depression at annual intervals; and daily single-item measures of self-concept clarity, identity commitments and reconsideration across three 5-day weeks. We examined (a) cross-lagged associations of selfconcept clarity to identity commitment and reconsideration and (b) associations of daily fluctuations in self and identity processes to later anxiety and depression. Results indicated that self-concept clarity and identity commitments influence one another reciprocally across days, and that day-to-day fluctuations in identity predicted later anxiety and depression. Results are discussed in terms of self and identity processes and their effects on distress. Copyright (C) 2010 John Wiley \& Sons, Ltd.
\end{abstract}

Key words: identity; self-concept clarity; daily measurement; anxiety; depression; early adolescence

\section{INTRODUCTION}

The study of the self has been one of the most enduring concerns in the social sciences. James (1890), one of the founders of modern psychology, devoted much of his writing to the ways in which people view themselves, and to the ways in which these self-views affect well-being, distress and personal relationships. Subsequent theorists, such as Erikson (1950), Rogers (1961), Maslow (1968) and May (1969), also focused considerable attention on who and what people think they are. These (and other) psychological theorists have written about the ways in which self-views develop and change over time.

However, the literature on self-perceptions has been quite fragmented, with different lines of research focusing on different aspects or domains of self (Schwartz, 2008). Indeed, although they use a common terminology, the various theoretical and empirical traditions have remained largely separate from one another (Vignoles, Schwartz, \& Luyckx, in press). A primary example of this has been the distinction between 'self' and 'identity' (Roeser, Peck, \& Nasir, 2006). Although Roeser et al. (2006) argue that 'self' and 'identity' are interchangeable, the conceptual and empirical overlap between self and identity has largely been unexplored (Côté \& Levine, 2002).

In the present study, we adopt the view that 'self' and 'identity' both represent part of the process of developing

*Correspondence to: Seth J. Schwartz, Department of Epidemiology and Public Health, Leonard M. Miller School of Medicine, University of Miami, 1425 N.W. 10th Avenue, Miami, FL 33199, USA.

E-mail: SSchwartz@med.miami.edu

${ }^{\dagger}$ Present address: Catholic University of Leuven in Belgium. a sense of who one is ( $c f$. Carver \& Scheier, 1982; Markus \& Nurius, 1986). Consistent with James (1890) and others (e.g. Côté \& Levine, 2002), 'identity' represents the process of searching for and settling on a set of commitments to personal standards and life roles (Meeus, Iedema, Helsen, \& Vollebergh, 1999), and 'self' represents the view of oneself that develops from (and influences) these commitments (Greenwald \& Pratkanis, 1985; Harter, 1999). Many constructs have been developed within the literature on self, including possible selves (Markus \& Nurius, 1986), self-discrepancy theory (Higgins, 1987) and control theory (Carver \& Scheier, 1982). We focus here on 'self-concept', which represents one's overall view of oneself in terms of competence, intelligence, and other attributes (Harter, 1999). More specifically, self-concept clarity (Campbell, 1990; Campbell, Assanand, \& Di Paula, 2003) refers to the extent to which individuals describe themselves in positive and consistent ways, and the extent to which individuals feel 'sure' of themselves. Self-concept clarity has been described as a key ingredient of both self-esteem (Story, 2004) and personal identity (Campbell, 1990).

\section{The role of consistency and clarity in personal identity and self-concept}

Although the term 'identity' has been used in many different ways (Brubaker \& Cooper, 2000; Côté, 2006), our use of the term is consistent with Erikson $(1950,1968)$. Erikson spoke of the extent to which a person has adopted a clear and internally consistent set of goals, values and beliefs-a dimension to which he referred as personal identity (see also 
Schwartz, 2005; Schwartz, Zamboanga, \& Weisskirch, 2008). A coherent sense of personal identity has been shown to be associated with positive outcomes such as self-esteem and life purpose (Schwartz, Côté, \& Arnett, 2005) and to protect against indicators of distress such as anxiety and depression (Schwartz, 2007). The operational definition of self-concept clarity corresponds very closely to this sense of coherence and of continuity across place and time (Campbell, Trapnell, Heine, Katz, Lavalee, \& Lehman, 1996) and may also be protective against anxiety and depression (Campbell et al., 2003).

\section{The role of psychosocial functioning}

Relationships with indices of psychosocial functioning (e.g. self-esteem, anxiety, depression) have been widely examined in both the self-concept (e.g. Campbell et al., 2003; Montague, Enders, Dietz, Dixon, \& Cavendish, 2008) and personal identity (Crocetti, Rubini, \& Meeus, 2008; Luyckx et al., 2008, 2010; Meeus et al., 1999) literatures. However, in most of these instances, psychosocial functioning has been considered - conceptually, empirically, or both-as a dependent or outcome variable. The way in which selfconcept clarity and identity on the one hand, and psychosocial adjustment on the other, affect each other over time has not been empirically investigated. It is not known whether earlier levels of anxiety and depression also affect later levels of identity and self-concept clarity.

In essence, then, we addressed two major issues in the present study: (a) the overlap and direction of effects between self-concept clarity and personal identity; and (b) the direction of effects between self-concept/identity and psychosocial functioning. It is important to use longitudinal research designs, because longitudinal data allows for empirically comparing different developmental sequences (Kraemer, Yesavage, Taylor, \& Kupfer, 2000). Further, we used an early adolescent sample, for whom identity is most likely to be unstable, and most apt to change, because early adolescents have only just begun to consider identity issues (e.g. Archer, 1982; Schwartz, Pantin, Prado, Sullivan, \& Szapocznik, 2005). Moreover, given this instability in identity development in early adolescence, we examined identity at a micro (daily) level, rather than at a macro (monthly or yearly) level (Klimstra, Luyckx, Hale, Frijns, van Lier, \& Meeus, 2010; Lichtwarck-Aschoff, van Geert, Bosma, \& Kunnen, 2008). Both of these last two issues are addressed immediately below.

\section{Identity in early adolescence}

Although self-concept research in general has been conducted on individuals of varying ages, most of the research on personal identity and self-concept clarity has been conducted with college students or other emerging adults (e.g. Constantino, Wilson, \& Horowitz, 2006; Luyckx et al., 2008), who are likely in the process of consolidating a sense of identity (Schwartz, 2005). When studying early adolescents, instability and fluctuation may be more common than stability as individuals begin to consider who they are and who they might want to become (Schwartz, Mason, Pantin, \& Szapocznik, 2009). The question then centres on the nature of these fluctuations and their effects on mental health in early adolescence.

The need to study self and identity at the micro-level Thus far, most longitudinal research on self and identity has examined macro-level fluctuations - that is, the ways in which people's views of themselves change over a number of months (e.g. Cole et al., 2001; Luyckx, Goossens, \& Soenens, 2006; Meeus et al., 1999; Montague et al., 2008). However, approaches assessing adolescents once every 6 or 12 months may provide a less precise portrayal of change processes-especially when change occurs frequently ( $c f$. Lerner, Schwartz, \& Phelps, 2009). Indeed, Lichtwarck-Aschoff et al. (2008) have argued that identity processes operate on a micro-level (weekly or even daily) basis. Although daily diary studies have been conducted on other aspects of identity (e.g. Yip, 2005; Yip \& Fuligni, 2002), to our knowledge only one study has conducted daily assessments of personal identity (Klimstra et al., 2010), and none have been conducted on self-concept clarity. Microlevel fluctuations in personal identity and self-concept, then, are in need of further study. Such studies would tell us (a) how identity operates on a daily basis, (b) the direction of effects between self-concept clarity and identity and (c) the direction of effects between identity/self-concept clarity and psychosocial functioning.

\section{Processes underlying personal identity development}

A number of models of personal identity state that identity development represents a dynamic between certainty/clarity and uncertainty/confusion (Erikson, 1968; Kroger \& Marcia, in press; Luyckx, Goossens, \& Soenens, 2006; Meeus, van de Schoot, Keijsers, Schwartz, \& Branje, 2010). The identity status model, for example, holds that identity is developed through a process of exploration-which involves suspension of commitments-followed by enactment of new commitments (or restoration of existing commitments; Kroger \& Marcia, in press). Luyckx, Goossens, Soenens, and Beyers (2006) have proposed an extension of the identity status framework, where commitments are formed through a process of exploring various alternatives, and where these commitments are then evaluated through a process of exploring them in depth. In studies drawn from both of these theoretical models, exploration in breadth is associated with confusion and distress, whereas commitment is associated with coherence and positive well-being (Luyckx et al., 2008; Schwartz, Zamboanga, Weisskirch, \& Rodriguez, 2009). The concept of commitment is similar to constructs drawn from other perspectives on identity, such as goals and personal projects (e.g. McGregor \& Little, 1998; Oosterwegel \& Oppenheimer, 2002). Like goals and personal projects, commitments provide a sense of meaning and direction to one's choices and life path (Bosma \& Kunnen, 2001), and they may facilitate well-being and protect against distress (Luyckx, Schwartz, Soenens, Vansteenkiste, \& Goossens, 2010).

Meeus and colleagues (Crocetti, Rubini, \& Meeus, 2008; Meeus et al., 2010) have extended the certainty-uncertainty dynamic even further and have cast this dynamic as the 
centre of their model. Specifically, commitment represents deciding to follow a specific course of action, whereas reconsideration of commitment represents discarding one's commitments and searching for new ones. Similar to the identity status studies, commitment has been found to be associated with positive well-being and inversely associated with distress, whereas reconsideration is associated with distress and negatively with well-being (Crocetti, Rubini, \& Meeus, 2008). Commitment should therefore lead to a positive sense of self, whereas reconsideration should undermine one's sense of self-although this hypothesis has not yet been empirically tested.

\section{Fluctuations as instability in identity}

Klimstra et al. (2010), using the same dataset used in the present study, used an innovative methodology (adapted from Kernis, Grannemann, \& Barclay, 1989, 1992) in their assessment of the day-to-day dynamics of identity commitment and reconsideration. They created an index of fluctuations in commitment and reconsideration by asking adolescents to complete single-item measures of these dimensions each day for five consecutive days, and then using the standard deviation of these five measurements as an index of fluctuation (for an application of the Kernis et al., 1989, standard deviation method using a single item measure of self-esteem, see also Oosterwegel, Field, Hart, \& Anderson, 2001). Fluctuations in reconsideration, but not in commitment, across days positively predicted reconsideration scores, and negatively predicted commitment scores, at the next annual assessment. This suggests that stopping and starting the reconsideration process may create a continuing sense of identity confusion in early adolescence. It follows, then, that the clarity of one's self-concept should be compromised in such cases-and that the identity confusion brought on by chronic reconsideration may be linked with symptoms of anxiety and depression (Crocetti, Schwartz, Fermani, \& Meeus, 2010; Meeus et al., 1999, 2010; Schwartz, Zamboanga, Weisskirch, \& Rodriguez, 2009). It is also possible, however, that anxiety and depression may precede reconsideration and may interfere with commitments and with the development of a clear sense of self (Crocetti, Klimstra, Keijsers, Hale, \& Meeus, 2009).

\section{The present study}

The present study was designed to examine the micro-level processes in identity and self-concept clarity, and their associations with anxiety and depression at the macro-level. Specifically, first, we sought to investigate the dynamics among identity commitment, reconsideration of identity commitments, and self-concept clarity at the day-to-day level. Given that commitments provide a sense of well-being and certainty (Luyckx, Schwartz, et al., 2010), and because relinquishing commitments undermines certainty and creates confusion (Meeus et al., 1999, 2010), we anticipated that commitment would facilitate self-concept clarity, whereas reconsideration would undermine self-concept clarity. Given that associations between identity and other aspects of self tend to be reciprocal (e.g. Luyckx, Goossens, \&
Soenens, 2006), we hypothesized that the relationship between identity and self-concept clarity would operate reciprocally as well.

Our second objective was to examine day-to-day fluctuations in identity commitments, reconsideration of identity commitments and self-concept clarity; and the extent to which these daily changes would predict macrolevel anxiety and depression. Because the literature on micro-level self and identity processes is so new, we drew on the macro-level identity and self-concept literature to generate hypotheses. Given the negative relationships found for both identity commitments (Crocetti et al., 2009; Luyckx, Goossens, \& Soenens, 2006) and self-concept (Campbell et al., 2003; Montague et al., 2008) with anxiety and depression, we hypothesized that identity commitments would be negatively related to anxiety and depression. We hypothesized a positive relationship for reconsideration with anxiety and depression (Crocetti et al., 2009).

The study was conducted in the Netherlands, which is one of the most common locations for identity research outside of North America (Waterman, 1999). A number of writers have called for the expansion of identity research (Schwartz, Adamson, Ferrer-Wreder, Dillon, \& Berman, 2006), and psychological research generally (Arnett, 2008), beyond the United States and Canada. The present study therefore has the potential to contribute to the continuing expansion of identity and self-concept research beyond North America.

\section{METHOD}

\section{Participants and procedure}

Data for the present study were taken from an ongoing longitudinal project entitled Research on Adolescent Development and Relationships (RADAR). All 6th grade elementary school classes in the province of Utrecht, and in the cities of Amsterdam, Rotterdam, The Hague and Almere were invited to participate in the assessment. Four hundred twenty-nine schools were randomly selected from the 850 primary education schools in these areas. Of these 429 schools, 296 agreed to participate, and data were collected at 230 of these 296 schools. Given the inclusion criteria for the larger RADAR project, all participating adolescents lived with both of their parents and had at least one sibling who was 10 years of age or older. Of the families of the 1544 adolescents who were randomly selected from the participating schools, 364 (24\%) did not meet inclusion criteria, $99(6 \%)$ were not reachable by telephone and $470(30 \%)$ declined to participate. Study variables did not differ significantly between adolescents who agreed to participate and those who declined (van Lier et al., 2010).

Of the 611 participating adolescents, 580 (318 boys and 262 girls) participated in at least one of the three Internet measurement weeks in 2006. These 580 adolescents $(54.8 \%$ boys; $45.2 \%$ girls; $M_{\text {age }}$ at the first Internet measurement $=$ $13.32, S D=0.53$, range $11-15$ ) comprise the sample for the present study. Participants completed these Internet 
measurements from home. Nearly all Dutch households (9598\%) had access to the Internet in 2006-2007 (Statistics Netherlands, 2010).

In each Internet assessment week, participants were asked to complete a questionnaire tapping into identity at a micro-level for five consecutive days. The initial Internet assessment took place in June 2006, and the second and third Internet assessments occurred 3 and 6 months later, respectively. Full-length annual assessments of self-concept clarity, anxiety and depression were conducted in FebruaryMarch 2006 and February-March 2007. Identity was assessed in the 2007 annual assessment, but not in the 2006 annual assessment. Supplemental analyses indicated that the 31 non-participating adolescents did not differ significantly from the 580 participating adolescents with regard to age, gender or socio-economic status.

Across all measurements, $13.3 \%$ of data were missing. Little's (1988) Missing Completely at Random (MCAR) test produced a statistically significant value for the daily identity and self-concept clarity variables, $\chi^{2}(8592)=$ 9228.07, $p<.001$, although the $\chi^{2} / d f$ ratio was only 1.07 . Similarly, for the annual assessments, the MCAR test produced a statistically significant value, $\chi^{2}(56)=75.19$, $p<.001$, although the $\chi^{2} / d f$ ratio was only 1.34 . These findings suggest that data were likely missing at random, and that maximum likelihood techniques were appropriate for use. Moreover, even when the assumption of missing completely at random is not met, the Full Information Maximum Likelihood (FIML) procedure is still preferable to listwise deletion of cases with missing data (McKnight, McKnight, Sidani, \& Figuredo, 2007). Listwise deletion results in a biased sample, and therefore biased results, by systematically excluding cases with missing data on any of the study variables. We therefore utilized FIML estimation using Mplus release 5.1 (Muthén \& Muthén, 2007).

\section{Measures \\ Commitment-reconsideration dynamic at the micro (daily) level}

To measure identity on a daily basis (i.e. at the micro-level), we used single-item subscales adapted from the UtrechtManagement of Identity Commitments Scale (U-MICS; Crocetti, Rubini, \& Meeus, 2008), a self-report measure of commitment and reconsideration. When participants are assessed on a daily basis, practice effects and participant burden become important issues to consider. Administering full scales to participants so frequently may create response sets and may more accurately reflect test-retest variability than true developmental change. On the other hand, posing a very general statement (e.g. 'I feel sure of myself today') may be less likely to create a response set-and such items have been used in experience sampling studies (e.g. Oosterwegel et al., 2001; Scollon, Kim-Prieto, \& Diener, 2003).

We used only the U-MICS ideological (educational) identity items, given that ideological domains of identity tend to be most closely related to other intrapersonal processes, and given that the educational domain is closely related to later career plans and success (e.g. Skorikov $\&$ Vondracek, in press). These single-item subscales were designed and validated by Klimstra et al. (2010). Similar to the full version of the U-MICS, 5-point Likert-scale items with a response format ranging from 1 (completely untrue) to 5 (completely true) were used. The items were 'Today, I felt confident about myself because of my education' (commitment) and 'Today, I strongly felt that I might be better off looking for a different education' (reconsideration). As reported by Klimstra et al. (2010), mean Heise (1969) reliability estimates for these single-item subscales, over three 5-day assessment weeks, ranged from .65 to .87 . The full version of the U-MICS, from which these items were drawn, has been shown to generate scores with strong internal consistency (Cronbach's $\alpha$ s ranged from .88 to .94) in Dutch samples (Crocetti, Rubini, Luyckx, \& Meeus, 2008; Crocetti, Rubini, \& Meeus, 2008). The factor structure of the full U-MICS has also been shown to be consistent across gender and ethnicity, and between early and middle adolescents (Crocetti, Rubini, \& Meeus, 2008).

\section{Self-concept clarity at the micro (daily) level}

As part of the present study, we also sought to validate a single-item measure of self-concept clarity. The single-item measure of self-concept clarity was designed based on the Self-Concept Clarity Scale (Campbell et al., 1996). The item reads, 'Today I had a clear picture of who and what I am'. This item was selected because it is positively worded and matches Campbell's definition of self-concept clarity, which refers to unity and consistency in one's sense of self (similar to Erikson's notion of temporal-spatial continuity). Psychometric properties of scores generated using this single-item scale are provided in the 'Results' section.

\section{Depression and anxiety at the macro-level}

As described in the 'Introduction' section, one of our objectives was to examine links between (a) fluctuations in identity commitments, reconsideration and self-concept clarity and (b) subsequent levels of anxiety and depression. We assessed depression using the Reynolds Adolescent Depression Scale (RADS; Reynolds \& Mazza, 1998), a 30-item measure designed to assess symptoms of clinical depression in adolescents. The RADS contains items targeting dysphoric mood, negative affect, negative self-evaluations and somatic complaints (e.g. headaches, tiredness, listlessness) - all of which represent symptoms of depression (e.g. Lang, Norman, Means-Christensen, \& Stein, 2009). At the first study timepoint following the daily assessments of identity and self-concept clarity, the Cronbach's $\alpha$ for RADS depression scores was .94 .

We assessed anxiety using the 38-item Screen for Child Anxiety-Related Emotional Disorders (SCARED; Birmaher, Khetarpal, Brent, Cully, Balach, \& Kaufman, 1997). The SCARED has been shown to produce valid and reliable scores in Dutch adolescent samples (Hale, Raaijmakers, Muris, \& Meeus, 2005). The measure assesses a number of components of anxiety, including panic, general anxiety, 
Table 1. Means and standard deviations for commitment and reconsideration across-week means and fluctuations in Internet weeks 1,2 and 3 , and mean levels at annual for target adolescents $(n=580)$

\begin{tabular}{|c|c|c|c|c|c|c|}
\hline & \multicolumn{2}{|c|}{ Week 1} & \multicolumn{2}{|c|}{ Week 2} & \multicolumn{2}{|c|}{ Week 3} \\
\hline & $\begin{array}{c}\text { Mean level } \\
\quad(M, S D)\end{array}$ & $\begin{array}{l}\text { Fluctuations } \\
\quad(M, S D)\end{array}$ & $\begin{array}{l}\text { Mean level } \\
\quad(M, S D)\end{array}$ & $\begin{array}{l}\text { Fluctuations } \\
\qquad(M, S D)\end{array}$ & $\begin{array}{l}\text { Mean level } \\
\quad(M, S D)\end{array}$ & $\begin{array}{l}\text { Fluctuations } \\
\quad(M, S D)\end{array}$ \\
\hline \multicolumn{7}{|l|}{ Ideological identity } \\
\hline Commitment & $3.24(0.83)$ & $0.63(0.45)$ & $3.13(0.82)$ & $0.55(0.44)$ & $3.08(0.81)$ & $0.54(0.45)$ \\
\hline Reconsideration & $1.52(0.74)$ & $0.37(0.43)$ & $1.49(0.67)$ & $0.30(0.40)$ & $1.68(0.87)$ & $0.34(0.42)$ \\
\hline Self-concept clarity & $2.70(0.87)$ & $0.95(0.65)$ & $2.75(0.84)$ & $0.92(0.77)$ & $2.69(0.81)$ & $0.80(0.67)$ \\
\hline
\end{tabular}

separation anxiety, school anxiety and social phobia. At the initial annual timepoint, the Cronbach's $\alpha$ for scores on the 38-item SCARED was .93 .

The full Self-Concept Clarity Scale and the U-MICS ideological identity commitment and reconsideration subscales at the macro-level were used only to validate the single-item self-concept clarity measure at the micro-level. Both of these measures use 5-point Likert-scale items, with a response format ranging from 1 (completely untrue) to 5 (completely true). The full Self-Concept Clarity Scale consists of 12 items assessing the extent to which one feels positively about oneself and believes that one is the same person across different situations and over time (Campbell et al., 1996). Cronbach's $\alpha$ in the present sample was .85 . For the U-MICS, within the ideological domain, five items measure commitment and 3 items measure reconsideration. Sample items are: 'My education gives me certainty in life' (commitment) and 'I often think it would be better to try and find different education' (reconsideration). Cronbach's $\alpha \mathrm{s}$ in the present sample were .94 for ideological commitment and .88 for ideological reconsideration.

\section{RESULTS}

\section{Objective 1: Validation of the single-item self-concept clarity measure}

\section{Reliability}

Ensuring that a scale generates valid and reliable scores is a necessary prerequisite to using this scale to test theory (Streiner, 2003). To establish the reliability of the single-item version of the Self-Concept Clarity Scale, we first assessed its internal consistency using a procedure developed by Heise (1969; see also Robins, Hendin, \& Trzesniewski, 2001). In this procedure, reliability of single-item scales is assessed with an estimate of test-retest reliability that separates true change from measurement error, with the following equation: $r_{x x}=\left(r_{12} \times r_{23}\right) / r_{13}$. As there were 5 days within each Internet week, we calculated three Heise estimates for each construct (commitment, reconsideration and self-concept clarity) for each week.

Additionally, to ensure that the Heise coefficients were not estimated for the same variables, and on the same dataset, used to conduct the primary analyses, we split the sample randomly in half. The first half-sample was used to estimate the Heise coefficients. The mean Heise coefficients were .67 for commitment, .74 for reconsideration, and .63 for self- concept clarity. Although these estimates are somewhat low, results with the single-item scale appeared to be consistent with theory and with prior findings, as described below. Additionally, as displayed in Table 1, there were considerable fluctuations in identity commitment, identity reconsideration, and self-concept clarity-and these day-to-day changes may have resulted in lower reliability coefficients.

\section{Convergent and discriminant validity}

Because identity micro-processes are assumed to fluctuate and change on a daily basis (Lichtwarck-Aschoff et al., 2008), it may not be reasonable to expect stability over time. However, assuming that this fluctuation occurs in a reasonably lawful manner, the micro-process assessments that occur closest to an annual assessment should be most strongly correlated with that annual assessment. These correlations should decrease as the micro-level measures are further removed from the annual assessment. To the extent that the micro- and macro-level identity processes correlate with one another over a relatively short span of time, this may reflect convergent validity between the micro- and macro-level measures.

Validity for the single-item SCCS was therefore established by calculating convergent and discriminant validity correlations between across-week means for the single-item micro-level measure and the full Self-Concept Clarity Scale at the previous and following assessment timepoint, and with the U-MICS at the following timepoint (the U-MICS was administered at the timepoint following the administration of the single-item measures, but not at the previous timepoint). The first randomly selected half-sample was again used for these analyses.

To estimate convergent validity, again using the first halfsample, we computed correlations of the single-item selfconcept clarity measure with the previous and subsequent full-version self-concept clarity measurements. We used the means for the first Internet week (closest to the previous annual assessment) and for the third Internet week (closest to the subsequent annual assessment) and correlated them with the previous and subsequent annual self-concept clarity scores. Pearson-Filon $z$-tests (Cohen \& Cohen, 1983 ) indicated that the week 1 self-concept clarity score was significantly more strongly correlated with the previous annual assessment $(r=.30, p<.04)$ than with the next annual assessment $(r=.04, p=.75), z=5.76, p<.001$. Similarly, the week 3 self-concept clarity score was significantly more strongly correlated with the next annual 
assessment $(r=.46, p<.001)$ than with the previous annual assessment $(r=.13, p=.07), z=7.79, p<.001$. Although these convergent validity correlations are smaller than might be expected, it must be kept in mind that microlevel and macro-level identity processes are measuring somewhat different types of processes (i.e. daily, somewhat unstable perceptions versus long-term, more stable perceptions; Lichtwarck-Aschoff et al., 2008).

In terms of discriminant validity, we examined correlations between the single-item measure of self-concept clarity (at Week 3) and the U-MICS commitment and reconsideration scales at the subsequent annual assessment. Although the U-MICS was not administered at the previous timepoint, correlations with the U-MICS at the following timepoint may be used to ascertain discriminant validity for the single-item Self-Concept Clarity measure. The correlations of the mean single-item self-concept clarity score were .46 with annual self-concept clarity, .27 with annual commitment and .13 with annual reconsideration. Pearson-Filon $z$-tests indicated that the correlation with subsequent annual measures of self-concept clarity was significantly larger compared to the corresponding correlations with annual measures of commitment, $z=4.21, p<.001$, or reconsideration, $z=5.69, p<.001$. The present analyses therefore provided some evidence for the convergent and discriminant validity of the single-item self-concept clarity measure. Klimstra et al. (2010) have found similar support for the convergent and discriminant validity of the single-item versions of the U-MICS commitment and reconsideration scales.

\section{Objective 2: Capturing the day-to-day dynamics between identity and self-concept}

The three weeks of Internet assessments each included five consecutive days of measurements for self-concept clarity, identity commitment and reconsideration of identity commitments. We were interested in examining the direction of effects between self-concept clarity and identity commitment and reconsideration in the ideological domain. As a result, we estimated two cross-lagged models, using the second randomly selected half-sample. Each model included self-concept clarity and one identity process (i.e. ideological commitment or reconsideration). In each model, paths from the identity process on Day $x$ were permitted to predict self-concept clarity on Day $x+1$, and vice versa. Autocorrelations for each process - correlations between the same variable on consecutive days-were also included in the model. Covariances were used to model concurrent (within-day) relationships between identity and self-concept clarity. Each autocorrelation and cross-path was constrained to be equal across days within a week (e.g. the Day 1-Day 2 paths were constrained to be equal to the Day 2-Day 3 paths). To ensure that these constraints did not significantly decrease model fit, we compared models with and without these constraints using differences in the $\chi^{2}$-value, the comparative fit index (CFI) and the non-normed fit index (NNFI). The difference in model fit between the constrained and unconstrained models can be assumed to be trivial provided that at least two out of three conditions are met: $\Delta \chi^{2}$ associated with a $p$-value greater than .05 (Byrne, 2001); $\Delta$ CFI less than .01 (Cheung \& Rensvold, 2002) and $\Delta$ NNFI less than .02 (Vandenberg \& Lance, 2000). Results indicated that these constraints did not significantly decrease model fit, $\Delta \chi^{2}(32)=96.30, \quad p<.001 ; \quad \Delta$ CFI $=.003$; $\Delta$ NNFI $<.001$.

Because we had three weeks of daily assessments, we constrained all corresponding paths to be equal across assessment weeks. Again, these constraints did not significantly decrease model fit, $\Delta \chi^{2}(12)=23.72$, $p<.03 ; \quad \Delta \mathrm{CFI}=.005 ; \quad \Delta \mathrm{NNFI}<.001$. We therefore had only one set of cross-lagged paths in each direction (identity $\rightarrow$ self-concept clarity and self-concept clarity $\rightarrow$ identity). We evaluated the fit of the commitment-selfconcept clarity model, and of the reconsideration-selfconcept clarity model, using the CFI, the NNFI and the root mean squared error of approximation (RMSEA). Good model fit is indicated by $\mathrm{CFI} \geq .95$, NNFI $\geq .90$ and RMSEA $\leq .08$ (Hancock \& Freeman, 2001). The chi-square index $\left(\chi^{\overline{2}}\right)$ is reported but is not used in interpretation, because it tests the null hypothesis of perfect fit to the data and is often inflated in complex models (Herzog, Boomsma, \& Reinecke, 2007; Kenny \& McCoach, 2003).

\section{Self-concept clarity and commitment}

The cross-lagged model examining associations between commitment and self-concept clarity fit the data well, $\chi^{2}(86)=114.09, \quad p<.04 ; \quad$ CFI $=.98 ; \quad$ NNFI $=.97$; RMSEA $=.037 \quad(90 \% \mathrm{CI}=.015-.054) \quad($ see Figure 1$)$. As the figure illustrates, self-concept clarity and ideological identity commitments were positively correlated within each day, and each process appeared to influence the other over the course of each week. The standardized cross-lagged path coefficients were $.09(p<.001)$ for the effect of selfconcept clarity on commitment, and $.07(p<.002)$ for the effect of commitment on self-concept clarity. These path

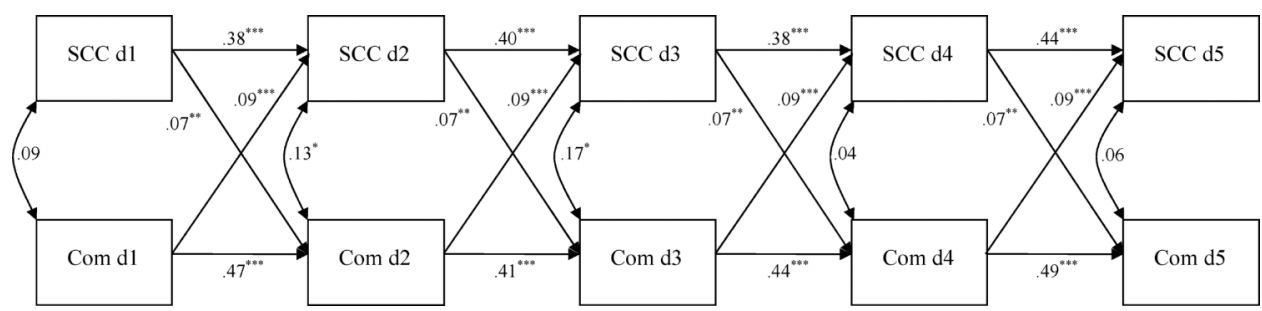

Figure 1. Commitment and self-concept clarity. 


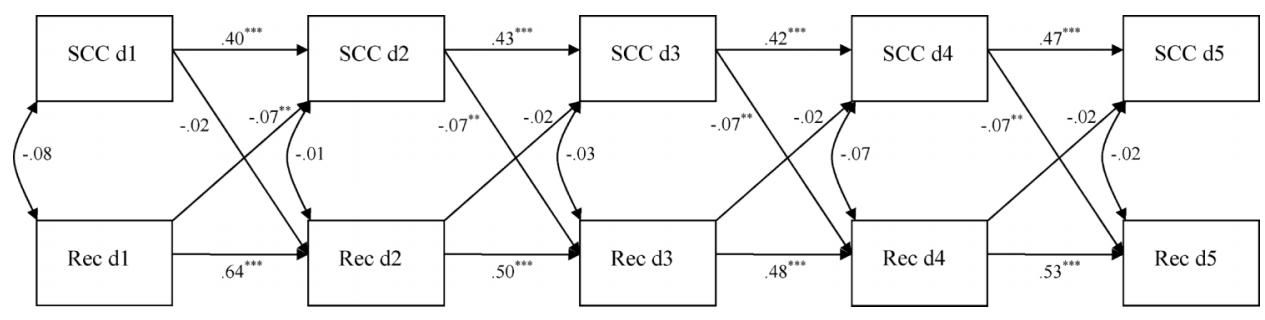

Figure 2. Reconsideration and self-concept clarity.

coefficients were not significantly different from one another, $\Delta \chi^{2}(1)=1.26, p=.26 ; \Delta \mathrm{CFI}=.001 ; \Delta \mathrm{NNFI}=$ .001 . This suggests that the association between commitment and self-concept clarity may be reciprocal.

\section{Self-concept clarity and reconsideration}

The cross-lagged model examining associations between ideological reconsideration and self-concept clarity fit the data reasonably well, $\chi^{2}(86)=164.80, p<.001 ; \mathrm{CFI}=.95$; $\mathrm{NNFI}=.92 ; \quad \mathrm{RMSEA}=.062 \quad(90 \% \mathrm{CI}=.048-.077) \quad(\mathrm{see}$ Figure 2). The cross-lagged path coefficient from reconsideration to self-concept clarity, $\beta=-.07, p<.005$, was larger than the cross-lagged path coefficient from self-concept clarity to reconsideration, $\beta=-.02, p=.19$. However, these path coefficients were not significantly different from one another, $\Delta \chi^{2}(2)=11.01, p<.005 ; \Delta \mathrm{CFI}=.005 ; \Delta \mathrm{NNFI}<.001$.

\section{Objective 3: Examining the influences of short-term fluctuations in identity and self-concept clarity on anxiety and depression}

To measure fluctuations in self-concept clarity, commitment and reconsideration, we calculated intra-person standard deviations separately, for each dimension, across the 5 days that comprised each daily assessment week (see Kernis et al., 1989; Klimstra et al., 2010). We used the full sample for this analysis, because these fluctuation scores were sufficiently different from the scores on which reliability and validity estimates were calculated (i.e. they were standard deviations calculated across 5 days, rather than single scores). Because three Internet weeks were available, there were three measurements of across-week fluctuations available for all three dimensions within each person. Sample means and standard deviations of fluctuation scores, and acrossweek mean-levels of commitment and reconsideration, are provided in Table 1.

Table 1 indicates that there were considerable withinweek fluctuations in self-concept clarity, as well as in ideological commitment and reconsideration. To examine the associations of these fluctuations with previous and subsequent levels of anxiety and depression, we estimated a model where (a) levels of anxiety and depression at the earlier annual assessment were allowed to predict fluctuations in self-concept clarity, identity commitment and reconsideration of identity commitments during each weekly assessment; and (b) fluctuations in self-concept clarity, identity commitment and reconsideration of identity commitments during each weekly assessment were allowed to predict levels of anxiety and depression at the subsequent annual assessment, controlling for previous levels of anxiety and depression. As was done for Objective 2, cross-lagged paths between fluctuations in commitment and fluctuations in reconsideration between successive Internet weeks were allowed, and autocorrelations in the fluctuation scores for each identity process in successive Internet weeks were estimated. For commitment, reconsideration, and selfconcept clarity, paths from earlier anxiety and depression scores to the weekly fluctuation scores were constrained equal across Internet weeks. The same was done for paths from weekly fluctuation scores to subsequent annual anxiety and depression scores. Although these constraints worsened model fit slightly, $\Delta \chi^{2}(16)=45.28, p<.001$; $\Delta \mathrm{CFI}=.020 ; \Delta \mathrm{NNFI}=.009$, the model results did not change as a result of this constraint.

The resulting model fit the data well, $\chi^{2}(31)=39.97$, $p=.13, \quad \mathrm{CFI}=.97, \quad \mathrm{NNFI}=.93, \quad$ RMSEA $=.038$ $(90 \% \mathrm{CI}=.000$ to .068$)$ (see Figure 3$)$. Autocorrelations among fluctuation scores were moderate, ranging from .15 to .28. The autocorrelations were strongest for reconsideration, suggesting that fluctuations in reconsideration were most likely to persist over time. In terms of cross-lagged associations between fluctuation scores, fluctuations in commitment predicted subsequent fluctuations in selfconcept clarity, $\beta=.08, p<.05$. None of the other cross-lagged paths reached or approached statistical significance. Fluctuations in reconsideration of commitments within weeks emerged as a significant predictor of both depression $(\beta$ 's were all $.09, p<.001)$, and anxiety $(\beta$ 's ranged from .04 to $.05, p<.05)$, at the next annual assessment. To ensure that it was the fluctuations, and not the mean levels of reconsideration per se that accounted for the significant prediction, we estimated a separate model where mean levels of commitment, reconsideration, and selfconcept clarity - averaged across assessment weeks-were allowed to predict anxiety and depression. By default, Mplus allows correlations among all pairs of exogenous variables, and among all pairs of endogenous variables. As a result, the model was just-identified and, by definition, provided a perfect fit to the data. However, controlling for fluctuation scores, none of the mean scores for the self and identity processes were significantly related to either anxiety or depression. The predictive effects of fluctuations in reconsideration remained significant when the means were included as predictors. This suggests that fluctuations in ideological reconsideration were predictive of anxiety and depression, regardless of the absolute levels of any of the 


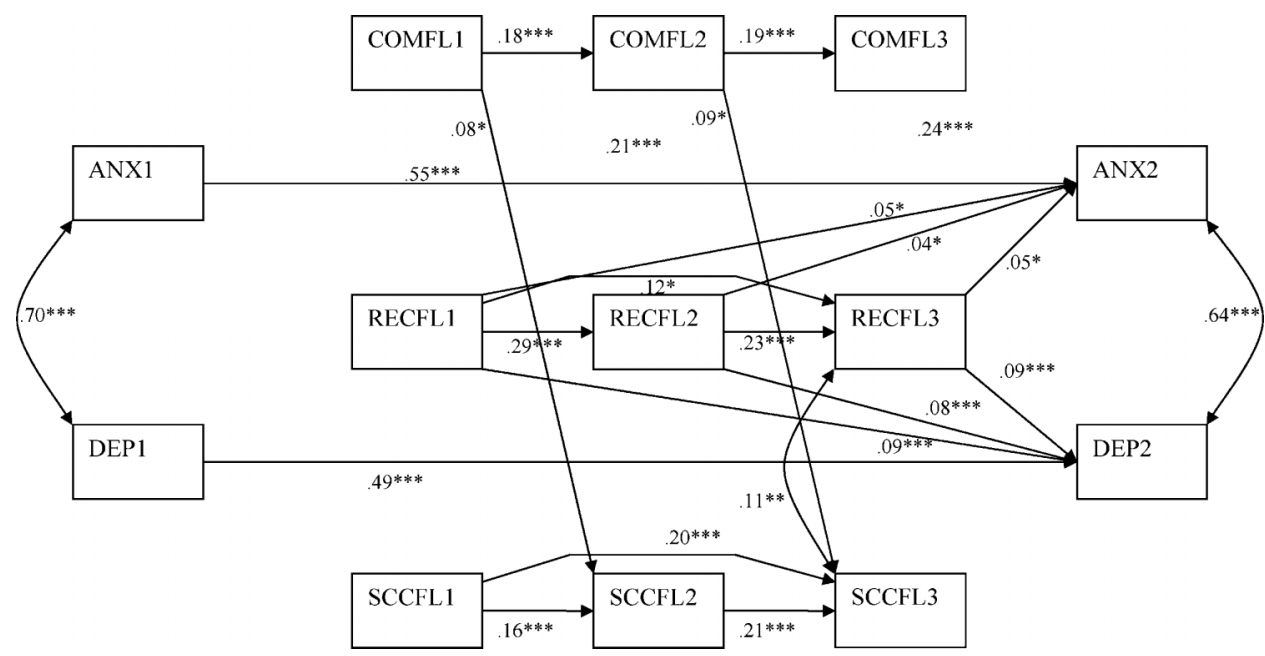

Figure 3. Fluctuations in identity and self-concept clarity as related to anxiety and depression. Note: Cross-sectional covariances among fluctuation scores are not displayed for the sake of clarity.

three processes. The fluctuations-more than the mean levels - of reconsideration appear to be most closely associated with anxiety and depression at the macro-level.

\section{DISCUSSION}

The present study was designed to examine (a) the daily dynamics between identity processes and self-concept clarity and (b) the effects of daily fluctuations in identity and selfconcept clarity on subsequent levels of anxiety and depression. Daily sequences of, and fluctuations in, identity and self-processes have been of theoretical interest for some time (Kerpelman, Pittman, \& Lamke, 1997; LichtwarckAschoff et al., 2008), but only recently have methodologies been developed to investigate these dynamics empirically. As suggested above, it is important to ascertain the extent to which the same predictive sequences operate at the microlevel as at the macro-level. Such knowledge would tell us whether the processes that operate over short spans of time are similar to, or different from, those that operate over longer spans of time. Moreover, the present study allowed us to evaluate the direction of effects between 'self' and 'identity' processes, which has rarely been examined in the literature.

Our first task was to provide validity and reliability evidence for the single-item measure of self-concept clarity used in the daily assessments. Heise (1969) estimates of stability were in the moderate range, suggesting some stability but also some fluctuation in self-concept clarity between days. Such a finding is consistent with research (De Hart \& Pelham, 2007; Kernis, 2005) suggesting that one's sense of self may fluctuate on a daily basis in response to external events, such as approval from others (e.g. Leary, 2004; Oosterwegel et al., 2001). The daily measure of selfconcept clarity was also reasonably associated with prior and subsequent annual measures of this same construct, providing some evidence for the validity of the single-item measure. However, the relatively low Heise reliability coefficients, and the somewhat low convergent validity correlations, may suggest that some caution should be exercised in interpreting the present results.

\section{Cross-lagged associations between identity and self- concept clarity}

Our second study objective was to examine the direction of day-to-day influences between identity commitment/reconsideration and self-concept clarity. We examined crosslagged path models across three separate weeks of assessments. A number of interesting and potentially important findings emerged from these analyses.

First, we found that the over-time associations between identity commitments and self-concept clarity appeared to be reciprocal. Forming strong commitments may help the person to maintain a strong sense of clarity about who and what $\mathrm{s} / \mathrm{he}$ is, and in turn, this sense of clarity may prompt the person to maintain her/his commitments. Moreover, as commitments change, clarity of self is likely to change as well. Such a conclusion is consistent with other work showing that the associations between personal identity and other aspects of self are largely reciprocal (e.g. Luyckx, 2006; Luyckx, Lens, Smits, \& Goossens, 2010).

Second, compared to commitment, reconsideration appeared to play a somewhat smaller role with regard to self-concept clarity at the daily level. Being committed to a sense of identity appears to be related to a sense of knowledge and confidence in who and what one is. Questioning or disregarding one's commitments from 1 day to the next may exert a smaller effect on clarity of self-knowledge. This may be a product of either the time span over which we were observing the cross-lagged relationships (i.e. daily) or the developmental period that characterized the sample (i.e. early adolescence). Instability and change are the norm in early adolescence, when advances in perspective taking and emotional development allow for the consideration of who one is or might become (Harter, Bresnick, Bouchey, \& Whitesell, 1997; Martin, Sokol, \& Elfers, 2008). Daily fluctuations in self-esteem or perceived clarity are also common in early adolescence 
and may be caused by approval or disapproval from friends, family, teachers or other significant people in the adolescent's life (Reynolds \& Repetti, 2008). Short-term fluctuations in self-concept clarity may, however, be more independent from decisions to reconsider the choices that one has made (or is in the process of making). Although reconsideration may represent uncertainty about who one might become, at the micro-level this seems to have a relatively small impact on one's overall sense of self. A different pattern may occur at the macro-level, where longer-term changes in identity, especially at older ages, may have much stronger effects on self-perceptions (Luyckx, Schwartz, Goossens, Soenens, \& Beyers, 2008). Short-term fluctuations in reconsideration may, however, have other consequences for longer-term functioning, as discussed below.

\section{Fluctuations in identity and self-concept clarity: Associations with anxiety and depression}

We then examined the extent to which day-to-day fluctuations in identity and self-concept processes would be linked with subsequent levels of anxiety and depression several months later. We used all three weeks of daily assessments (with the assessment weeks separated by about 3 months), so that we would be able to make a more general statement about the effects of short-term fluctuations over the course of a year. Results indicated that fluctuations in reconsideration across all three daily assessment weeks were predictive of both depression and anxiety at the next annual assessment, controlling for previous levels of anxiety and depression. This was not the case for fluctuations in either commitment or self-concept clarity.

These findings suggest that reconsideration, as an index of suspending or abandoning commitments, may create a sense of disequilibrium and distress. This may be especially true in cases where reconsideration is started or stopped (i.e. when it fluctuates). Importantly, this appears to be the case regardless of the absolute levels of reconsideration reported. It is the change in (un)certainty across days that appears to predict distress in early adolescents. When early adolescents become more or less willing to suspend or discard their commitments, confusion and distress may follow. The identity development process itself, which represents a dynamic between certainty and uncertainty (Meeus et al., 2010), may therefore contribute to distress (e.g. Luyckx et al., 2008; Schwartz, Zamboanga, Weisskirch, \& Rodriguez, 2009). In some cases, when individuals are 'stuck' in a chronic state of reconsideration, more severe distress may result, and clinical intervention may be necessary - as we note below.

Additionally, the associations of identity reconsideration with anxiety and depression appeared to be unidirectional, with reconsideration predicting anxiety and depression, but not vice versa, over time. The present study is among the first to suggest empirically that self and identity processes may precede psychosocial functioning. This finding implies that confusion regarding identity processes serves as a precursor to feelings of distress, but not vice versa. Intervening to promote successful identity development may therefore serve as a way to prevent or alleviate distress in adolescence.

Combining the present results with those reported by Klimstra et al. (2010) using the same dataset suggests that, at the micro-level, reconsideration leads to decreases in commitment, which in turn may lead to decreases in selfconcept clarity. Fluctuations in reconsideration between days may have a doubly negative effect-destabilizing the self by undermining commitments and weakening the clarity and coherence of the self-concept-as well as contributing to anxiety and depression by inducing confusion. Some identity confusion is necessary for healthy identity development, as existing commitments must be set aside before one can explore new roles, relationships and goals (Meeus et al., 2010). This confusion may lead to some distress, especially in early adolescence as the task of developing a sense of self and identity is initiated (Arnett, 1999; Schwartz, Mason, et al., 2009). However, excessive changes in reconsideration may paralyse the person and make it extremely difficult to make important decisions regarding who one is or will be (Luyckx, Schwartz, Goossens, Soenens, et al., 2008). In other words, fluctuations in reconsideration indicate a degree of disorganization in one's self-perceptions, perhaps reflecting what Erikson (1968) referred to as an identity crisis.

Overall, the present study, along with earlier work, suggests a dynamic between commitment and self-concept clarity, as found in the present study, along with the certainty-uncertainty dynamic identified in Klimstra et al. (2010) and in Meeus et al. (2010). One must find the optimal balance between making commitments and reconsidering or revising them (Bosma \& Kunnen, 2001; LichtwarckAschoff et al., 2008; Luyckx, Goossens, \& Soenens, 2006). To the extent that one is able to maintain commitments, a clear and coherent sense of self may result. However, when one becomes 'stuck' in the daily process of developing a sense of identity - especially when one is not willing or able to stop thinking about what choices to make-large fluctuations in reconsideration may occur, and negative outcomes may result. For example, Schwartz, Mason, et al. (2009) found a group of U.S. Hispanic early adolescents whose identity confusion scores increased during early and middle adolescence. These adolescents were at increased risk for cigarette, alcohol and drug initiation, as well as initiation of unprotected sexual behaviour. Further observation of the adolescents in the present sample will be necessary to determine whether this is also the case with Dutch adolescents.

With respect to possible clinical implications of this study, one finding that stands out is the effect of fluctuations in adolescent reconsideration on subsequent levels of adolescent depression and anxiety (controlling for levels of anxiety and depression at the measurement time of reconsideration). As we previously noted, these fluctuations in reconsideration may indicate a change in (un)certainty that leads to higher depression and anxiety levels in adolescents. We additionally noted that these fluctuations might be comparable to ruminating about identity-related choices, similar to the cross-sectional findings reported by 
Luyckx, Schwartz, Goossens, and Pollock (2008) that specifically examined adolescent ruminative exploration and adolescent well-being. It would seem that, for some individuals, this uncertainty (or ruminating) about what choices one might or might not make, may be analogous to the Generalized Anxiety Disorder (GAD) symptoms of worry. GAD worry has been defined as a process of repeatedly re-thinking, or re-considering, one's actual behavioural choices (e.g. Borkovec \& Inz, 1990). In a recent study of adolescent GAD worry symptoms, Hale, Klimstra, and Meeus (2010) suggested that adolescent GAD worry may be more akin to a personality trait than a state, and that these symptoms may require longer Cognitive Behaviour Therapy (CBT) personality trait protocols (i.e. more treatment sessions) than is presently the case for anxiety disorder state protocols. In light of the present longitudinal findings, it seems that a specific type of adolescent GAD worry-reconsideration fluctuations or chronic ruminative exploration-may represent a risk for future adolescent depression and anxiety disorders. Hence, we would advise therapists who encounter chronic identity confusion, anxiety, and depression to signal this pattern to the adolescent, and also to consider that the CBT psychotherapeutic interventions may require more time (due to the ingrained personality trait character of this worry) than simple anxiety (state) interventions. Adolescents who struggle with chronic indecisiveness may be in need of in-depth clinical intervention (Luyckx, Schwartz, Goossens, \& Pollock, 2008)

\section{Strengths, limitations and future directions}

The present study is characterized by several strengths, as well as a number of important limitations. Perhaps the most important strength of the current study is its focus on day-today micro-processes of identity formation, which have been identified as an important research direction (Grotevant, 1987; Kunnen, Bosma, \& van Geert, 2001; LichtwarckAschoff et al., 2008) but which have received only limited empirical attention. Second, we included three dailyassessment weeks, each consisting of 5 days, and findings appeared to be extremely similar across weeks. We were also able to relate the day-to-day dynamics of identity development to more long-term psychosocial processes in theoretically consistent ways.

Despite these strengths, the present study is characterized by a number of important limitations. First, although identity activity begins in early adolescence (Archer, 1982), the majority of identity activity occurs during later adolescence and emerging adulthood. There may have been more variability, and stronger findings, observed with an older age group. Identity exploration, for example, requires perspective-taking and advanced formal-operational skills (Berman, Schwartz, Kurtines, \& Berman, 2001) that, for some adolescents, may not be available until later adolescence. On the other hand, for some adolescents, identity exploration may already be underway-as evidenced by the tendency for some adolescents to report reconsidering their current commitments.
Second, although the single-item scales were presented daily during each of the three Internet weeks, the content of these items was quite general (e.g. 'Today I had a clear picture of who and what I am'). It may be more informative to include items targeting specific aspects of self, such as physical appearance, academic competence, or likability to peers (Harter, 1999). On the other hand, the use only of items related to education to assess identity may underrepresent the identity construct, especially given that identity may operate differently across content domains (Goossens, 2001). Such more nuanced items may also be more easily understood by early adolescents. Items assessing multiple identity domains, such as family relationships, career plans and religious or spiritual beliefs, may provide a more complete portrayal of the adolescent's sense of identity.

Third, the present analyses were limited to self-concept clarity. Other aspects of self, such as self-esteem (Luyckx, Goossens, Soenens, \& Beyers, 2006) and self-determined functioning (Soenens, Berzonsky, Vansteenkiste, Beyers, \& Goossens, 2005), remain to be examined as correlates of identity micro-processes. It is not known whether similar or discrepant findings would have emerged had a different aspect of self been studied.

Fourth, we did not consider interpersonal processes (e.g. acceptance or rejection from peers, parents, teachers and other significant others) that might have set the certaintyuncertainty dynamic in motion. There is evidence, for example, that interactions with peers (Kerpelman \& Pittman, 2001) and with family members (Meeus, Oosterwegel, \& Vollebergh, 2002) help to drive the process of identity development, as well as changes in self-concept (Harter, 1999b). Future research should include interpersonal relationships in the study of day-to-day changes in self and identity processes.

Fifth, it is possible that repeated questioning about identity issues may have prompted rumination about these issues ( $c f$. Moberly \& Watkins, 2008). This may be particularly salient in early adolescence, when individuals are likely first considering potential identity commitments in areas such as career and friendships and have likely not made firm commitments in these areas. Indeed, as Luyckx, Schwartz, Goossens, and Pollock (2008) have found, ruminating about identity-related choices, without coming to a comfortable resolution, is associated with anxiety and depression. In our results, reconsideration-which may carry a ruminative tone-was most closely associated with anxiety and depression. We do not know the extent to which daily assessment of reconsideration may have encouraged participants to reconsider or ruminate about their choices. Experience sampling methods (e.g. Scollon et al., 2003), where individuals are paged daily and asked to report on their thoughts and feelings, might be less likely to prompt participants to ruminate about their choices-because no specific questions are asked about identity. However, it should be noted that only five questions were asked about identity and self-concept each day, and that these five questions were embedded within a much longer daily assessment battery. Moreover, in Table 1, mean scores for reconsideration did not increase across Internet weeks, and 
mean scores for self-concept clarity did not decrease across assessment weeks. Increased rumination would likely have resulted in an increase in reconsideration and a decrease in self-concept clarity over time.

Despite these limitations, the present study has made a number of potentially important contributions, including studying self-concept and identity together, examining the direction of effects between the two domains of self-perception, and linking micro-processes of identity development with macro-level psychosocial functioning. We hope that the present study inspires more research along these lines, and that the specific day-to-day processes underlying self and identity development begin to receive the empirical attention that they merit.

\section{ACKNOWLEDGMENTS}

Data from the Research on Adolescent Development and Relationships (RADAR) study were used. RADAR has been financially supported by main grants from the Netherlands Organisation for Scientific Research (GBMAGW 480-03-005, GB-MAGW 480-08-006), and Stichting Achmea Slachtoffer en Samenleving (SASS), and various other grants from the Netherlands Organisation for Scientific Research, VU University Amsterdam, and Utrecht University.

\section{REFERENCES}

Archer, S. L. (1982). The lower age boundaries of identity. Child Development, 53, 1551-1556.

Arnett, J. J. (1999). Adolescent storm and stress, reconsidered. American Psychologist, 54, 317-326.

Arnett, J. J. (2008). The neglected 95\%: Why American psychology needs to become less American. American Psychologist, 63, 602614.

Berman, A. M., Schwartz, S. J., Kurtines, W. M., \& Berman, S. L. (2001). The process of exploration in identity formation: The role of style and competence. Journal of Adolescence, 24, 513-528.

Birmaher, B., Khetarpal, S., Brent, D., Cully, M., Balach, L., \& Kaufman, K. (1997). The screen for child anxiety related emotional disorders (SCARED): Scale construction and psychometric characteristics. Journal of the American Academy of Child and Adolescent Psychiatry, 36, 545-553.

Borkovec, T. D., \& Inz, J. (1990). The nature of worry in generalized anxiety disorder: A predominance of thought activity. Behaviour Research and Therapy, 28, 153-158.

Bosma, H. A., \& Kunnen, E. S. (2001). Determinants and mechanisms in ego identity development: A review and synthesis. Developmental Review, 21, 39-66.

Brubaker, R., \& Cooper, F. (2000). Beyond 'identity'. Theory and Society, 29, 1-47.

Byrne, B. M. (2001). Structural equation modeling with AMOS: Basic concepts, applications, and programming. Mahwah, NJ: Lawrence Erlbaum Associates.

Campbell, J. D. (1990). Self-esteem and clarity of the self-concept. Journal of Personality and Social Psychology, 59, 538-549.

Campbell, J. D., Assanand, S., \& Di Paula, A. (2003). The structure of the self-concept and its relation to psychological adjustment. Journal of Personality, 71, 115-140.
Campbell, J. D., Trapnell, P. D., Heine, S. J., Katz, I. M., Lavallee, L. F., \& Lehman, D. R. (1996). Self-concept clarity: Measurement, personality correlates, and cultural boundaries. Journal of Personality and Social Psychology, 70, 141-156.

Carver, C. R., \& Scheier, M. F. (1982). Control theory: A useful conceptual framework for personality-social, clinical, and health psychology. Psychological Bulletin, 92, 111-135.

Cheung, G. W., \& Rensvold, R. B. (2002). Evaluating goodness-offit indexes for testing measurement invariance. Structural Equation Modeling, 9, 233-255.

Cohen, J., \& Cohen, P. (1983). Applied multiple regression/ correlation analysis for the behavioral sciences (2nd ed.). Hillside, NJ: Lawrence Erlbaum Associates.

Cole, D. A., Maxwell, S. E., Martin, J. M., Lachlan, G. P., Seroczynski, A. D., Tram, J. M., et al. (2001). The development of multiple domains of child and adolescent self-concept: A cohort sequential longitudinal design. Child Development, 72, $1723-1746$.

Constantino, M. J., Wilson, K. R., \& Horowitz, L. M. (2006). The direct and stress-buffering effects of self-organization on psychological adjustment. Journal of Social and Clinical Psychology, 25, 333-360.

Côté, J. E. (2006). Identity studies: How close are we to developing a social science of identity? An appraisal of the field. Identity: An International Journal of Theory and Research, 6, 3-26.

Côté, J. E., \& Levine, C. G. (2002). Identity formation, agency, and culture: A social psychological synthesis. Mahwah, NJ: Lawrence Erlbaum Associates.

Crocetti, E., Klimstra, T. A., Keijsers, L., Hale, W. W., \& Meeus, W. (2009). Anxiety trajectories and identity development in adolescence: A five-wave longitudinal study. Journal of Youth and Adolescence, 38, 839-849.

Crocetti, E., Rubini, M., Luyckx, K., \& Meeus, W. (2008). Identity formation in early and middle adolescents from various ethnic groups: From three dimensions to five statuses. Journal of Youth and Adolescence, 37, 983-996.

Crocetti, E., Rubini, M., \& Meeus, W. (2008). Capturing the dynamics of identity formation in various ethnic groups: Development and validation of a three-dimensional model. Journal of Adolescence, 31, 207-222.

Crocetti, E., Schwartz, S. J., Fermani, A., \& Meeus, W. (2010). The Utrecht Management of Identity Commitments Scale (U-MICS): Italian validation and cross-national comparisons. European Journal of Psychological Assessment, 26, 169-183.

De Hart, T., \& Pelham, B. W. (2007). Fluctuations in state implicit self-esteem in response to daily negative events. Journal of Experimental Social Psychology, 43, 157-165.

Erikson, E. H. (1950). Childhood and society. New York: Norton.

Erikson, E. H. (1968). Identity: Youth and crisis. New York: Norton.

Goossens, L. (2001). Global versus domain-specific statuses in identity research: A comparison of two self-report measures. Journal of Adolescence, 24, 681-699.

Greenwald, A. G., \& Pratkanis, A. R. (1985). How shall the self be conceived? Journal for the Theory of Social Behaviour, 15, 311329.

Grotevant, H. D. (1987). Toward a process model of identity formation. Journal of Adolescent Research, 2, 203-222.

Hale, W. W. III, Klimstra, T. A., \& Meeus, W. (2010). Is the generalized anxiety disorder symptom of worry just another form of neuroticism?: A five-year longitudinal study of adolescents from the general population. Journal of Clinical Psychiatry, 71, 942-948.

Hale, W. W. III, Raaijmakers, Q., Muris, P., \& Meeus, W. (2005). Psychometric properties of the screen for child anxiety related emotional disorders (SCARED) in the general adolescent population. Journal of the American Academy of Child and Adolescent Psychiatry, 44, 283-290.

Hancock, G. R., \& Freeman, M. J. (2001). Power and sample size for the root mean square error of approximation test of not close 
fit in structural equation modeling. Educational and Psychological Measurement, 61, 741-758.

Harter, S. (1999). The construction of the self. New York: Guilford Press.

Harter, S., Bresnick, S., Bouchey, H. A., \& Whitesell, N. R. (1997). The development of multiple role-related selves during adolescence. Development and Psychopathology, 9, 835-853.

Heise, D. R. (1969). Separating reliability and stability in test-retest correlation. American Sociological Review, 34, 93-101.

Herzog, W., Boomsma, A., \& Reinecke, S. (2007). The model-size effect on traditional and modified tests of covariance structures. Structural Equation Modeling, 14, 361-390.

Higgins, E. T. (1987). Self-discrepancy theory: What patterns of self-beliefs cause people to suffer? In L. Berkowitz (Ed.), Advances in experimental social psychology (Vol. 22, pp. 93136). San Diego, CA: Academic Press.

James, W. (1890). Principles of psychology (Vols 1-2). New York: Holt.

Kenny, D. A., \& McCoach, D. B. (2003). Effect of the number of variables on measures of fit in structural equation modeling. Structural Equation Modeling, 10, 333-351.

Kernis, M. H. (2005). Measuring self-esteem in context: The importance of stability of self-esteem in psychological functioning. Journal of Personality, 73, 1569-1605.

Kernis, M. H., Grannemann, B. D., \& Barclay, L. C. (1989). Stability and level of self-esteem as predictors of anger arousal and hostility. Journal of Personality and Social Psychology, 56, 1013-1023.

Kernis, M. H., Grannemann, B. D., \& Barclay, L. C. (1992). Stability of self-esteem: Assessment, correlates, and excuse making. Journal of Personality, 60, 621-644.

Kerpelman, J. L., \& Pittman, J. F. (2001). The instability of possible selves: Identity processes within late adolescents' close peer relationships. Journal of Adolescence, 24, 491-512.

Kerpelman, J. L., Pittman, J. F., \& Lamke, L. K. (1997). Toward a microprocess perspective on adolescent identity development: An identity control theory approach. Journal of Adolescent Research, 12, 325-346.

Klimstra, T. A., Luyckx, K., Hale, W. W., III, Frijns, T., van Lier, P. A. C., \& Meeus, W. H. J. (2010). Short-term fluctuations in identity: Introducing a micro-level approach to identity formation. Journal of Personality and Social Psychology, 99, 191-202.

Kraemer, H. C., Yesavage, J. A., Taylor, J. L., \& Kupfer, D. (2000). How can we learn about developmental processes from crosssectional studies, or can we? American Journal of Psychiatry, 157, 163-171.

Kroger, J., \& Marcia, J. E. (in press). The Identity statuses: Origins, meanings, and interpretations. In S. J. Schwartz, K. Luyckx, \& V. L. Vignoles (Eds.) Handbook of identity theory and research. New York: Springer.

Kunnen, E. S., Bosma, H. A., \& van Geert, P. (2001). A dynamic systems approach to identity formation: Theoretical background and methodological possibilities. In J.-E. Nurmi (Ed.), Navigating through adolescence: European perspectives. New York: Garland.

Lang, A. J., Norman, S. B., Means-Christensen, A., \& Stein, M. B. (2009). Abbreviated brief symptom inventory for use as an anxiety and depression screening instrument in primary care. Depression and Anxiety, 26, 537-543.

Leary, M. (2004). The sociometer, self-esteem, and the regulation of interpersonal behavior. In R. F. Baumeister, \& K. D. Vohs (Eds.), Handbook of self-regulation: Research, theory and applications (pp. 373-391). New York: Guilford Press.

Lerner, R. M., Schwartz, S. J., \& Phelps, E. (2009). Problematics of time and timing in the longitudinal study of human development: Theoretical and methodological issues. Human Development, 52, 44-68.

Lichtwarck-Aschoff, A., van Geert, P., Bosma, H., \& Kunnen, S. (2008). Time and identity: A framework for research and theory formation. Developmental Review, 28, 370-400.
Little, R. J. A. (1988). A test of missing completely at random for multivariate data with missing values. Journal of the American Statistical Association, 83, 1198-1202.

Luyckx, K. (2006). Identity formation in emerging adulthood: Developmental trajectories, antecedents, and consequences. Unpublished Doctoral Dissertation, Katholieke Universiteit Leuven, Belgium.

Luyckx, K., Goossens, L., \& Soenens, B. (2006). A developmental contextual perspective on identity construction in emerging adulthood: Change dynamics in commitment formation and commitment evaluation. Developmental Psychology, 42, 366-380.

Luyckx, K., Goossens, L., Soenens, B., \& Beyers, W. (2006). Unpacking commitment and exploration: Preliminary validation of an integrative model of late adolescent identity formation. Journal of Adolescence, 29, 361-378.

Luyckx, K., Lens, W., Smits, I., \& Goossens, L. (2010). Time perspective and identity formation: Short-term longitudinal dynamics in college students. International Journal of Behavioral Development, 34, 238-247.

Luyckx, K., Schwartz, S. J., Berzonsky, M. D., Soenens, B., Vansteenkiste, M., Smits, I., et al. (2008). Capturing ruminative exploration: Extending the four-dimensional model of identity formation in late adolescence. Journal of Research in Personality, $42,58-82$.

Luyckx, K., Schwartz, S. J., Goossens, L., \& Pollock, S. (2008). Employment, sense of coherence, and identity formation. Journal of Adolescent Research, 23, 566-591.

Luyckx, K., Schwartz, S. J., Goossens, L., Soenens, B., \& Beyers, W. (2008). Developmental typologies of identity formation and adjustment in female emerging adults: A latent class growth analysis. Journal of Research on Adolescence, 18, 595-619.

Luyckx, K., Schwartz, S. J., Soenens, B., Vansteenkiste, M., \& Goossens, L. (2010). The path from identity commitments to adjustment: Motivational underpinnings and mediating mechanisms. Journal of Counseling and Development, 88, 52-60.

Markus, H. R., \& Nurius, P. (1986). Possible selves. American Psychologist, 41, 954-969.

Martin, J., Sokol, B. W., \& Elfers, T. (2008). Taking and coordinating perspectives: From preflective interactivity, through reflective intersubjectivity, to metareflective sociality. Human Development, 51, 294-317.

Maslow, A. (1968). Toward a psychology of being. New York: Wiley \& Sons.

May, R. (1969). Love and will. New York: Norton.

McGregor, I., \& Little, B. R. (1998). Personal projects, happiness, and meaning: On doing well and being yourself. Journal of Personality and Social Psychology, 74, 494-512.

McKnight, P. E., McKnight, K. M., Sidani, S., \& Figueredo, A. J. (2007). Missing data: A gentle introduction. New York: Guilford.

Meeus, W., Iedema, J., Helsen, M., \& Vollebergh, W. (1999). Patterns of adolescent identity development: Review of literature and longitudinal analysis. Developemental Review, 19, 419-461.

Meeus, W., Oosterwegel, A., \& Vollebergh, W. (2002). Parental and peer attachment and identity development in adolescence. Journal of Adolescence, 25, 93-106.

Meeus, W., van de Schoot, R., Keijsers, L., Schwartz, S. J., \& Branje, S. (2010). On the progression and stability of adolescent identity formation: A five-wave longitudinal study in earlyto-middle and middle-to-late adolescence. Child Development, $88,1565-1581$.

Moberly, N. J., \& Watkins, E. R. (2008). Ruminative self-focus and negative affect: An experience sampling study. Journal of Abnormal Psychology, 117, 314-323.

Montague, M., Enders, C., Dietz, S., Dixon, J., \& Cavendish, W. M. (2008). A longitudinal study of depressive symptomology and self-concept in adolescents. Journal of Special Education, 42, 67-78.

Muthén, L. K., \& Muthén, B. (2007). Mplus user's guide (5th ed.) Los Angeles: Muthén \& Muthén. 
Oosterwegel, A., Field, N., Hart, D., \& Anderson, A. (2001). The relation of self-esteem variability to emotion variability, mood, personality traits, and depressive tendencies. Journal of Personality, 59, 689-708.

Oosterwegel, A., \& Oppenheimer, L. (2002). Jumping to awareness of conflict between self-representations and its relation to psychological well-being. International Journal of Behavioral Development, 26, 548-555.

Reynolds, W. M., \& Mazza, J. J. (1998). Reliability and validity of the Reynolds adolescent depression scale with young adolescents. Journal of School Psychology, 36, 295-312.

Reynolds, B. M., \& Repetti, R. L. (2008). Contextual variations in negative mood and state self-esteem. Journal of Early Adolescence, 28, 405-427.

Robins, R. W., Hendin, H. M., \& Trzesniewski, K. H. (2001). Measuring global self-esteem: Construct validation of a singleitem measure and the Rosenberg self-esteem scale. Personality and Social Psychology Bulletin, 27, 151-161.

Roeser, R. W., Peck, S. C., \& Nasir, N. S. (2006). Self and identity processes in school motivation and achievement In P. A. Alexander, \& P. H. Winne (Eds.), Handbook of educational psychology (2nd ed., pp. 391-424). Mahwah, NJ: Lawrence Erlbaum.

Rogers, C. (1961). On becoming a person. New York: Houghlin Mifflin.

Schwartz, S. J. (2005). A new identity for identity research: Recommendations for expanding and refocusing the identity literature. Journal of Adolescent Research, 20, 293-308.

Schwartz, S. J. (2007). The structure of identity consolidation: Multiple correlated constructs or one superordinate construct. Identity: An International Journal of Theory and Research, 7, 27-49.

Schwartz, S. J. (2008). Self and identity in early adolescence: Some reflections and an introduction to the special issue. Journal of Early Adolescence, 28, 5-15.

Schwartz, S. J., Adamson, L., Ferrer-Wreder, L., Dillon, F. R., \& Berman, S. L. (2006). Identity status measurement across contexts: Variations in measurement structure and mean levels among White American, Hispanic American, and Swedish emerging adults. Journal of Personality Assessment, 86, 61-76.

Schwartz, S. J., Côté, J. E., \& Arnett, J. J. (2005). Identity and agency in emerging adulthood. Youth and Society, 37, 201-229.

Schwartz, S. J., Mason, C. A., Pantin, H., \& Szapocznik, J. (2009). Longitudinal relationships between family functioning and identity development in Hispanic adolescents. Journal of Early Adolescence, 29, 177-211.

Schwartz, S. J., Pantin, H., Prado, G., Sullivan, S., \& Szapocznik, J. (2005). Family functioning, identity, and problem behavior in Hispanic immigrant early adolescents. Journal of Early Adolescence, 25, 392-420.
Schwartz, S. J., Zamboanga, B. L., \& Weisskirch, R. S. (2008). Broadening the study of the self: Integrating the study of personal identity and cultural identity. Social and Personality Psychology Compass, 2, 635-651.

Schwartz, S. J., Zamboanga, B. L., Weisskirch, R. S., \& Rodriguez, L. (2009). The relationships of personal and ethnic identity exploration to indices of adaptive and maladaptive psychosocial functioning. International Journal of Behavioral Development, 33, 131-144.

Scollon, C. N., Kim-Prieto, C., \& Diener, E. (2003). Experience sampling: Promises and pitfalls, strengths and weaknesses. Journal of Happiness Studies, 4, 5-34.

Skorikov, V. B., \& Vondracek, F. W. (in press). Occupational identity. In S. J. Schwartz, K. Luyckx, \& V. L. Vignoles (Eds.), Handbook of identity theory and research. New York: Springer.

Soenens, B., Berzonsky, M. D., Vansteenkiste, M., Beyers, W., \& Goossens, L. (2005). Identity styles and causality orientations: In search of the motivational underpinnings of the identity exploration process. European Journal of Personality, 19, 427-442.

Statistics Netherlands. (2010). Statline: ICT gebruik van personen naar persoonskenmerken [ICT use of individuals by individual characteristics]. Voorburg, The Netherlands: Author.

Story, A. L. (2004). Self-esteem and self-certainty: A mediational analysis. European Journal of Personality, 18, 115-125.

Streiner, D. L. (2003). Being inconsistent about consistency: When coefficient alpha does and doesn't matter. Journal of Personality Assessment, 80, 217-222.

Vandenberg, R. J., \& Lance, C. E. (2000). A review and synthesis of the measurement invariance literature: Suggestions, practices, and recommendations for organizational research. Organizational Research Methods, 3, 4-70.

van Lier, P. A. C., Frijns, T., Blokland, E. D. E., Neumann, A., Koot, H., \& Meeus, W. (2010). The RADAR study: design, description of sample and validation of cohort assignment. Manuscript submitted for publication.

Vignoles, V. L., Schwartz, S. J., \& Luyckx, K. (in press). Introduction: Toward an integrative view of identity. In S. J. Schwartz, K. Luyckx, \& V. L. Vignoles (Eds.), Handbook of identity theory and research. New York: Springer.

Waterman, A. S. (1999). Identity, the identity statuses, and identity status development: A contemporary statement. Developmental Review, 19, 591-621.

Yip, T. (2005). Sources of situational variation in ethnic identity and psychological well-being: A palm pilot study of Chinese American students. Personality and Social Psychology Bulletin, 31, 1603-1616.

Yip, T., \& Fuligni, A. J. (2002). Daily variation in ethnic identity, ethnic behaviours, and psychological well-being among American adolescents of Chinese decent. Child Development, $73,1557-1572$. 